\title{
Composite Compound Free Flaps for Lateral Malleolar Reconstruction
}

\author{
Bruno Battiston, MD, PhD ${ }^{1}$ Pierfrancesco Pugliese, MD $\quad$ Stefano Artiaco, MD ${ }^{1} \quad$ Davide Ciclamini, MD ${ }^{1}$ \\ Michele Cillino, $\mathrm{MD}^{1}$ Pierluigi Tos, MD, $\mathrm{PhD}^{1}$ \\ 1 U.O.C Musculoskeletal Traumatology, U.O.D. Microsurgery, C.T.O. \\ Hospital, Torino, Italy \\ J Reconstr Microsurg Open 2016;1:39-41. \\ Address for correspondence Pierfrancesco Pugliese, MD, U.O.C \\ Musculoskeletal Traumatology, U.O.D. Microsurgery, C.T.O. Hospital, \\ Via Gianfranco Zuretti, 29, 10126, Torino, Italy \\ (e-mail: pierfrancescopugliese@hotmail.com).
}

Shortening or absence of the distal fibula may cause a clinically valgus hindfoot owing to the talar abduction and lateral rotation. ${ }^{1,2}$ A displacement of $1 \mathrm{~mm}$ or 30-degree lateral rotation could alter the load distribution and lead to an abnormal articular stress causing subsequent arthritis. ${ }^{3-5}$

In case of loss of both bone and soft tissue, a reconstructive treatment is mandatory in order to restore skin coverage and a functional ankle with long-term stability.

We present two results of a one-stage reconstruction of the complex lateral malleolus traumatic defect with two different microsurgical composite compound flaps.

\section{Patients and Method}

\section{Case 1}

A 25-year-old man with a subtotal defect of the left lateral malleolus and a $10 \times 6 \mathrm{~cm}$ skin defect because of a motorbike accident was treated with a combined iliac crest bone and iliacus muscle flap plus a split-thickness skin graft, revascularized in an end-to-end fashion on the peroneal vessels.

Two screws were used to lock the iliac graft and reconstruct the tibiofibular syndesmosis (TFS). This decision was made intraoperatively because of impairment of ligamentous structures and instability of the ankle. Screws were removed 90 days after the procedure.

At 5-month control, magnetic resonance imaging (MRI) showed good morphology of the articular surface of the ankle joint. At 13-year control, X-ray images showed a tibiofibular arthrodesis and no signs of arthritis with a flexo-extension of the tibiotalar joint comparable to the contralateral one (-Figs. 1 and $\mathbf{2}$ ).

\section{Case 2}

An 11-year-old girl presented a traumatic defect of partial left lateral malleolus with an associated $12 \times 22 \mathrm{~cm}$ skin defect, as a result of a car accident. We performed a free received

June 22, 2015

accepted after revision

September 27, 2015

published online

March 17, 2016 combined serratus muscle and ninth rib bone flap plus a split-thickness skin graft, revascularized in an end-to-end fashion on the anterior tibial vessels. Plate was employed to give stability and external support, thereby allowing an early mobilization.

The plate and screws were removed on day 180. Clinical control showed good mobility and stability of the ankle. The flap was too bulky, and required secondary liposuction to improve the cosmetic result.

At 7-year follow-up, X-ray images showed a well-integrated rib with a restored continuity of the bone and preservation of TFS. Plantar flexion of the ankle was 50 degrees and dorsal flexion 10 degrees (-Figs. 3 and $\mathbf{4}$ ).

\section{Discussion}

Loss of tissue in the foot and ankle region represents a challenging problem because of the small number of local flaps available close to the structures involved in walking and load bearing.

In case 1 , as the tibiofibular ligaments were severely damaged, we fixed the bone with screws passing through three cortical structures for a tighter reconstruction to perform a tibiofibular arthrodesis leaving the tibiotalar joint free. The function and mobility of the ankle were good, and the patient did not experience any problems from the procedure in his daily life.

In case 2 , we proposed to perform bone synthesis with plate and screws, which would then be removed later, to leave the TFS free for future growth. Because of the necessity to cover the synthesis, we needed a bone flap with a larger component of soft tissue than in case 1 , and the serratus muscle proved to be a good choice. Later on, a further operation was necessary just to improve the aesthetic outcome, and long-term radiograms showed the perfect rib insetting, leaving the TFS intact, and how its light curvature
Copyright $\odot 2016$ by Thieme Medical Publishers, Inc., 333 Seventh Avenue, New York, NY 10001, USA. Tel: +1(212) 584-4662.
License terms

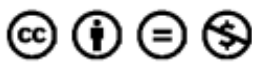

10.1055/s-0035-1570537. ISSN 2377-0813. 


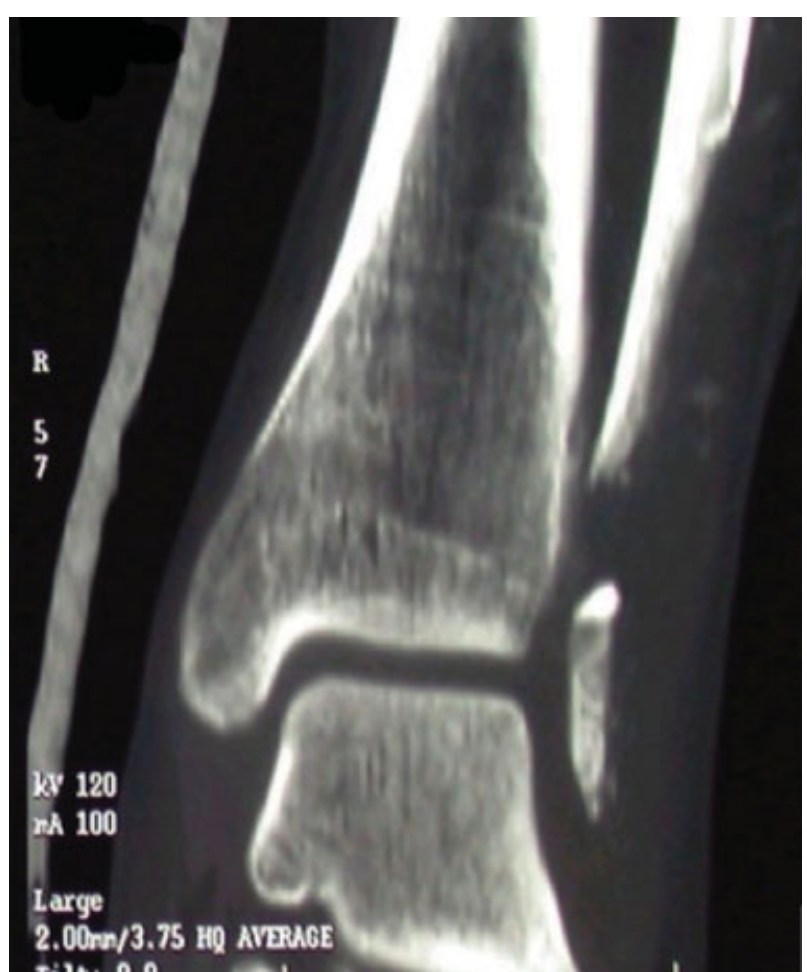

Fig. 1 Case 1: preoperative computed tomography in frontal view.

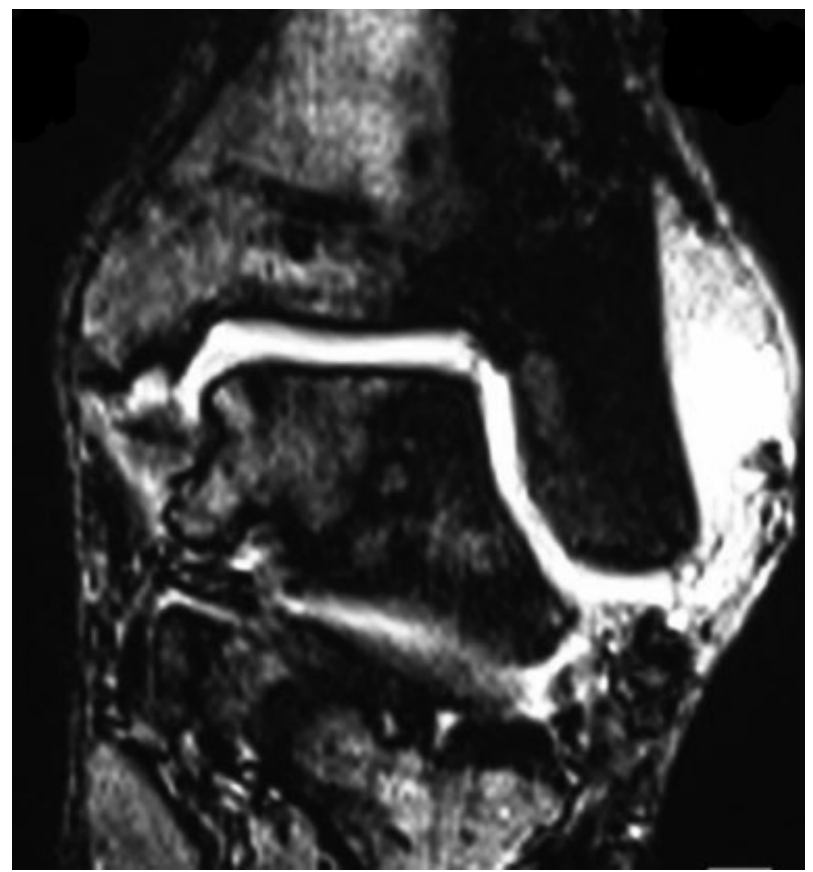

Fig. 2 Case 1: 5-month postoperative MRI in frontal view.

allowed a good anatomical support to the remaining osteochondral part of the lateral malleolus.

Recently, cases employing a medial femoral condyle flap have been published, but only for tibiotalar articulation. This option with low donor-site morbidity has many advantages, providing a composite graft for more complex defects including cartilage, if needed. ${ }^{6}$ In other reports, the proximal head of fibula has been employed to restore a

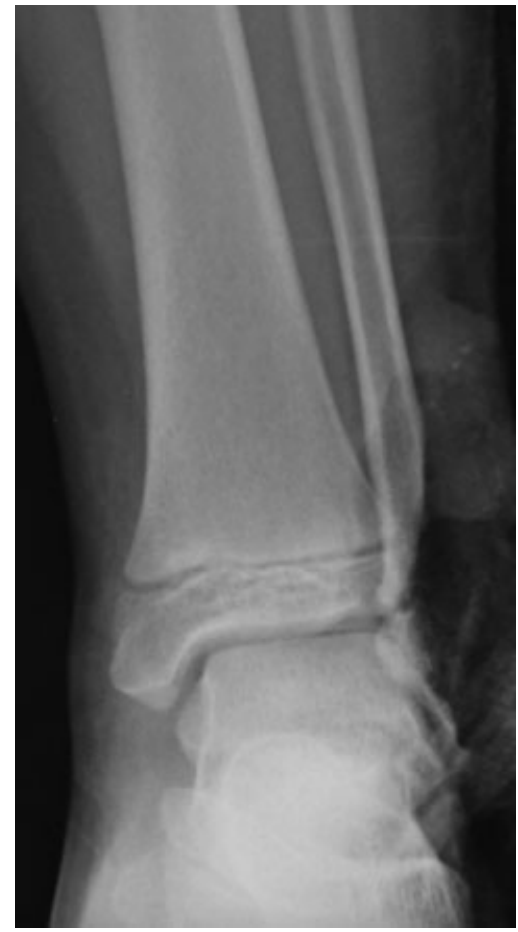

Fig. 3 Case 2: preoperative X-rays in frontal view.

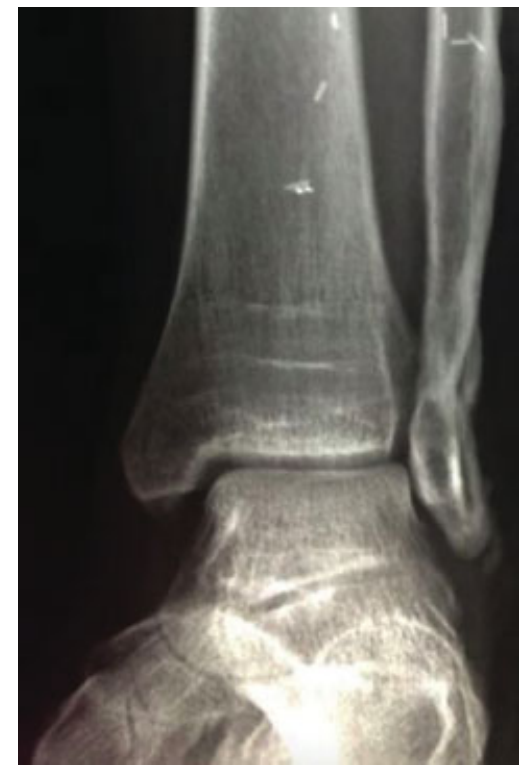

Fig. 4 Case 2: 7-year postoperative X-rays in frontal view.

composite bone and soft tissue defect of the medial malleolus with good results. ${ }^{7,8}$ More recently, latissimus dorsi flap plus scapula or with rib has been used for composite reconstruction in the lower limbs with good results. ${ }^{9,10}$

In our opinion, the reconstruction of the lateral malleolus is more demanding than the medial one and needs different solutions, as in our cases, according to the shape of the defect, 
the involvement of the tibiofibular joint, and the amount of soft tissues needed.

In the first case, the patient did not experience either iliac bulging or loss of strength of the abdominal wall; in the second one, the only negative aspect to the donor site was just the scar. Healing was uneventful, without major complications, evaluated with a long-term follow-up (13 and 7 years, respectively, for case 1 and 2 ), and results were very satisfactory. Being a runner, the 25-year-old man is placing his ankle under great stress and he has experienced no problems. Similarly, the 11-year-old girl has continued to dance.

We believe it is preferable to restore integrity to the original tibiofibular structure rather than conservative treatment, but as the large variability of lesions, patients, and general conditions precludes the possibility to postulate an unequivocal indication for ankle restoration, we cannot assert that surgical reconstruction is better than another.

Given that each case is different, it seems that the different solutions that we adopted were well matched with the kind of loss of tissue and with the patients themselves.

If it is necessary to use plates and screws, it is mandatory to take into account the need to ensure their adequate coverage; using screws alone we have less need for soft tissue coverage, but with the risk of a reduction in the physiological function of the TFS. In our case, however, this did not affect the final function of the ankle.

\section{Conclusion}

The repair of bone defects with free bone grafting in terminal position is at high risk of secondary reabsorption: vascularized bone flap avoids this complication. Adding vascularized soft tissues in a combined fashion allows complete anatomical reconstruction and safe coverage of the internal osteosynthesis. Surgeons should use the best flap according to not only the amount of tissue to be reconstructed but also the site and function of the involved segment. Microvascular flaps give this possibility of complete anatomical and functional restoration even in such complex cases.

\section{References}

1 Wiltse LL. Valgus deformity of the ankle: a sequel to acquired or congenital abnormalities of the fibula. J Bone Joint Surg Am 1972; 54(3):595-606

2 Lambert KL. The weight-bearing function of the fibula. A strain gauge study. J Bone Joint Surg Am 1971;53(3):507-513

3 Kimizuka M, Kurosawa H, Fukubayashi T. Load-bearing pattern of the ankle joint. Contact area and pressure distribution. Arch Orthop Trauma Surg 1980;96(1):45-49

4 Wang Q Whittle M, Cunningham J, Kenwright J. Fibula and its ligaments in load transmission and ankle joint stability. Clin Orthop Relat Res 1996;(330):261-270

5 Yablon IG, Heller FG, Shouse L. The key role of the lateral malleolus in displaced fractures of the ankle. J Bone Joint Surg Am 1977; 59(2):169-173

6 Mattiassich G, Marcovici LL, Dorninger L, et al. Reconstruction with vascularized medial femoral condyle flaps in hindfoot and ankle defects: a report of two cases. Microsurgery 2014;34(7):576-581

7 Liu Y, Zhang CJ, Fu XM, Wang JL, Wang CQ. Fibular head composite flap for bone and skin defect at medial malleolus in children: a report of 4 cases [in Chinese]. Zhonghua Zheng Xing Wai Ke Za Zhi 2011;27(2):95-97

8 Wu SP. Clinical study of reconstructing the medial malleolus with free grafting of fibular head composite tendon bone flap. Chin J Traumatol 2008;11(1):34-36

9 Junnila J, Repo JP, Mustonen A, Tukiainen EJ. Treatment of compound tibial fracture with free osteomuscular latissimus dorsi scapula flap. J Reconstr Microsurg 2015;31(3):217-224

10 Sia WT, Xu GG, Puhaindran ME, Tan BK, Cheng MH, Chew WY. Reconstruction of extensive soft-tissue defects with concomitant bone defects in the lower extremity with the latissimus dorsiserratus anterior-rib free flap. J Reconstr Microsurg 2015;31(6): 407-413 